06,13

\title{
Электро- и магнетотранспорт в области межфазной границы $\mathrm{LaAlO}_{3} / \mathrm{SrTiO}_{3}$
}

\author{
() Ю.А. Бойков, В.А. Данилов, И.Т. Серенков, В.И. Сахаров, М.П. Волков \\ Физико-технический институт им. А.Ф. Иофрфе РАН, \\ Санкт-Петербург, Россия \\ E-mail: yu.boikov@mail.ioffe.ru
}

(Поступила в Редакцию 12 декабря 2017 г.)

Сопоставление каналовых спектров рассеяния ионов средних энергий, визуализированных для гетероструктур $\mathrm{LaAlO}_{3} /(001) \mathrm{SrTiO}_{3}$ с толщиной слоя алюмината лантана от одной до шести элементарных ячеек, свидетельствует о том, что слой алюмината лантана растет когерентно на поверхности $\mathrm{TiO}_{2}$ терминированной подложки из титаната стронция. Сопротивление межфазной границы в гетероструктуре с толщиной слоя $\mathrm{LaAlO}_{3}$ в 6 элементарных ячеек уменьшалось с температурой. При $T<100 \mathrm{~K}$ положительное магнетосопротивление и холловская подвижность электронов резко возрастали с понижением температуры.

Финансовая поддержка данного исследования была частично получена от проектов РФФИ № 15-02-03996а и № 15-02-99476а и из Программы Президиума РАН „Наноструктуры“, подпрограмма № 1.

DOI: 10.21883/FTT.2018.06.46004.346

\section{1. Введение}

Появление наноразмерной прослойки квазидвумерного электронного газа на межфазной границе между $\mathrm{TiO}_{2}$ терминированной подложкой из титаната стронция и выращенной на ее поверхности пленкой алюмината лантана индуцировало проведение активных исследований состава, структуры и электронных параметров гетероструктур $\mathrm{LaAlO}_{3} /(001) \mathrm{SrTiO}_{3}$ (LAO/STO) [1-3].

Было показано [1], что проводимость межфазной границы между двух указанных выше широкозонных диэлектриков зависит от давления кислорода $\left(\mathrm{P}_{\mathrm{O} 2}\right)$ в ростовой камере в процессе формированиия гетероструктуры. Высокой проводимостью обладают межфазные границы в гетероструктурах с толщиной $(d)$ слоя LAO в четыре и более элементарных ячеек (u.c.), сформированных при низком $\left(\mathrm{P}_{\mathrm{O} 2} \leq 10^{-4} \mathrm{mbar}\right)$ давлении кислорода. Проводимость таких гетероструктур не исчезает [4] после их термообработки $\left(T \approx 600^{\circ} \mathrm{C}\right)$ при относительно высоком ( 300 mbar) давлении кислорода.

Катастрофа полярности [1], высокая концентрация кислородных вакансий [3] и катионные замещения $(\mathrm{La} \leftrightarrow \mathrm{Sr})$ [4] в области межфазной границы отмечались в качестве возможных механизмов, влияющих на проводимость последней. Механические напряжения, возникающие вследствие рассогласования в параметрах кристаллических решеток алюмината лантана и титаната стронция, могут также оказывать существенное влияние на зарядовое состояние межфазной границы в гетероструктуре LAO/STO [5].

\section{2. Эксперимент}

Пленки LAO с толщиной до шести элементарных ячеек были сформированы методом лазерного испарения.
Технологические условия формирования пленок LAO на поверхности $\mathrm{TiO}_{2}$ терминированных подложек (100)STO детализированы в [4].

Данные о стехиометрии и структуре межфазных границ также, как и оценки степени покрытия поверхности подложки слоем алюмината лантана в сформированных гетероструктурах, были получены с использованием спектроскопии рассеяния ионов средних энергий (MEIS, $\mathrm{He}^{+}, E=96 \mathrm{keV}$ ), каналовый и рэндом (квазислучайный) спектры. При измерении каналовых спектров пучок ионов гелия был направлен вдоль нормали к плоскости подложки, т. е. параллельно [001]STO, а при визуализации рэндом спектров пучок ионов гелия был отклонен от нормали к плоскости подложки на 8 градусов. Важной отличительной особенностью спектроскопии MEIS является аномально высокое разрешение состава по толщине.

Температурные зависимости сопротивления $(R)$ выращенных гетероструктур были измерены в конфигурации van der Pauv в магнитном поле $H$ и без него $\left(\mu_{0} \mathrm{H}\right.$ до $14 \mathrm{~T})$. Магнитное поле было направлено перпендикулярно плоскости подложки.

\section{3. Результаты и их обсуждение}

Спектры MEIS, измеренные в режиме рэндом для гетероструктур LAO/STO с толщиной $(d)$ слоя LAO в 4 u.c. и в 5 u.c., показаны на рис. 1. При рассеянии на тяжелых атомах лантана ионы $\mathrm{He}^{+}$теряют меньше энергии, чем при рассеянии на легких атомах ( $\mathrm{Sr}, \mathrm{Ti}$, $\mathrm{Al}$ и т.д.), поэтому пик лантана на визуализированных спектрах четко разрешается. Интеграл под пиком лантана пропорционален количеству атомов La в гетероструктуре, а полуширина пика зависит от их распределения по ее толщине. 
Каналовые спектры MEIS, визуализированные для гетероструктур LAO/STO с толщиной слоя алюмината лантана в одну и в четыре элементарные ячейки, показаны на вставке на рис. 1. На спектре, полученном для гетероструктуры LAO/STO с толщиной слоя LAO в одну элементарную ячейку четко видны пики лантана и стронция. C увеличением толщины слоя LAO до четырех элементарных ячеек интенсивность пика лантана возрастала, а интенсивность пика стронция резко деградировала. Уменьшение интенсивности пика стронция на каналовом спектре с увеличением $d$ свидетельствует о том, что слой LAO растет когерентно на поверхности STO, причем атомы лантана находятся в тех же кристаллографических рядах, что и атомы $\mathrm{Sr}$, и эффективно их экранируют от участия в рассеянии ионов $\mathrm{He}^{+}$.

Проведенный в [4] сравнительный анализ экспериментальнах спектров MEIS, визуализированных в режиме рэндом, с результатами моделирования [6] свидетельствует о катионных замещениях ( $\mathrm{La} \leftrightarrow \mathrm{Sr}$ ), происходящих в процессе формирования гетероструктуры, причем атомы лантана неоднородно распределяются в плоскости подложки. Покрытие свободной поверхности гетероструктуры слоем LAO возрастает с увеличением толщины осажденного слоя LAO, однако, даже при $d=6$ u. с. слой алюмината лантана в LAO/STO не полностью покрывает свободную поверхность гетероструктуры. Следует отметить, что в результате катионных замещений в прослойке подложки STO, прилегающей к границе с осажденной пленкой LAO, присутствовало значительное количество атомов лантана.

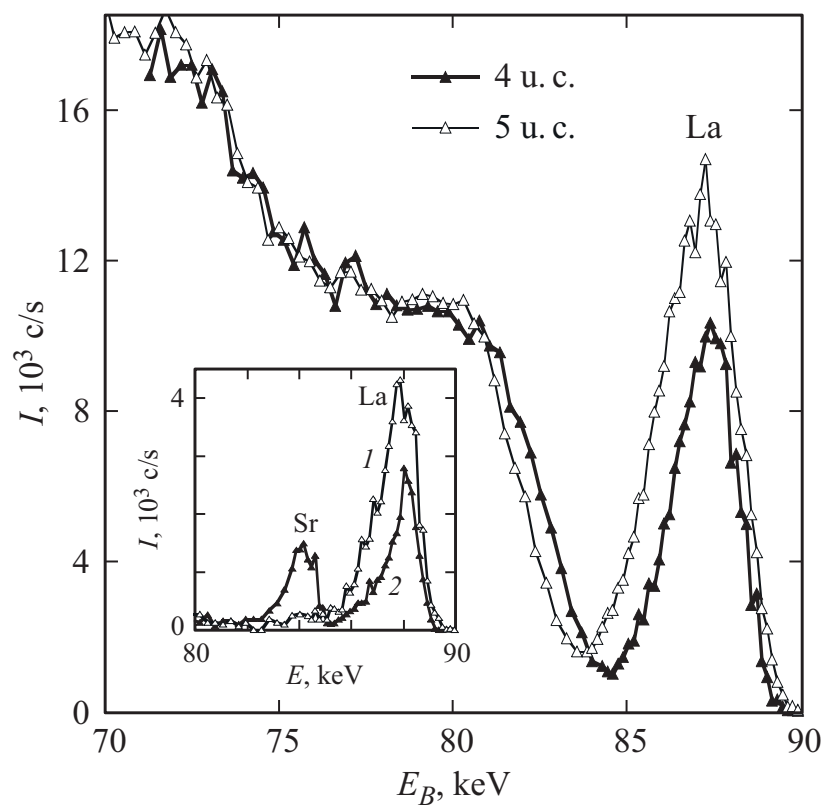

Pис. 1. Спектры MEIS, визуализированные в режиме рэндом для гетероструктур LAO/STO с толщиной слоя алюмината лантана в 4 u.c. и 5 u.c.. На вставке показаны каналовые спектры MEIS, измеренные для гетероструктур LAO/STO с толщиной слоя LAO в одну (2) и в четыре (1) элементарные ячейки.

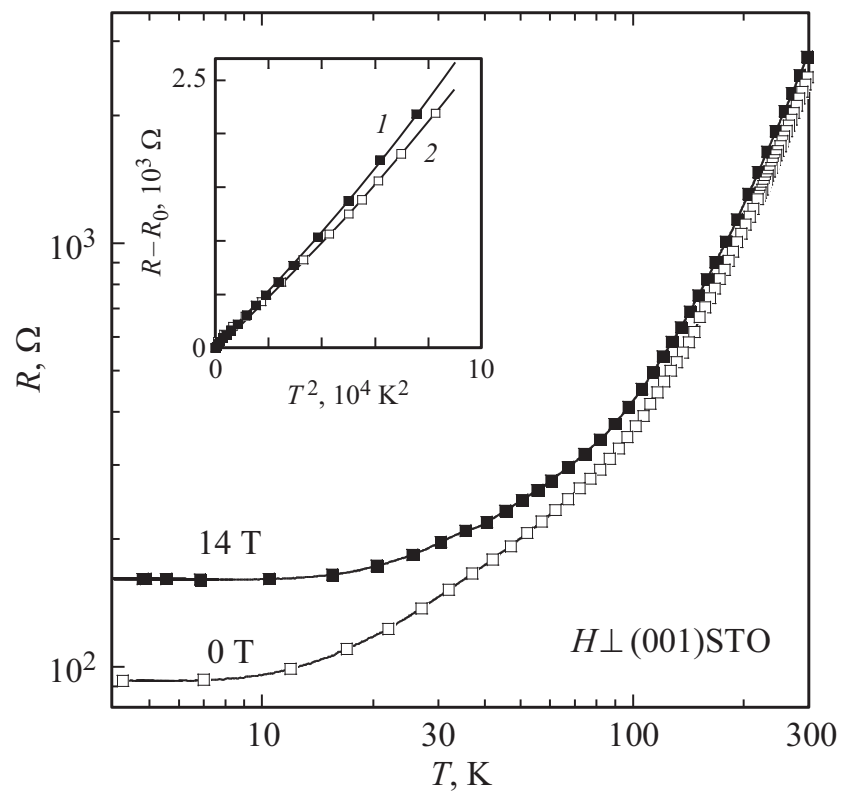

Рис. 2. Температурные зависимости сопротивления межфазной границы в гетероструктуре LAO/STO $(d=6$ u.c.), измеренные при $\mu_{0} \mathrm{H}=0$ и $\mu_{0} \mathrm{H}=14 \mathrm{~T}$. Зависимости $\left(R-R_{0}\right) v s T^{2}$, для той же гетероструктуры в магнитном поле $(1)$ и без него (2) показаны на вставке.

На интенсивность катионных замещений в гетероструктуре существенное влияние могут оказывать неоднородные механические напряжения в подложке и ступени на ее поверхности с высотой в одну элементарную ячейку, включения $\mathrm{SrCO}_{3}$ [7] и двухслойные пакеты из окиси титана [8].

Замещение атомов стронция в STO на атомы лантана из формируемой пленки LAO приводит к увеличению концентрации электронов в приповерхностном слое гетероструктуры. Вклад электронов, появившихся в результате катионных замещений, в латеральную проводимость межфазной границы в гетероструктуре LAO/STO зависит как от количества атомов лантана, диффундировавших в подложку, так и от их распределения в плоскости подложки.

На рис. 2 приведены измеренные в магнитном поле и без него температурные зависимости сопротивления гетероструктуры LAO/STO с толщиной слоя алюмината лантана в 6 u.c., а на рис. 3 - температурная зависимость магнетосопротивления межфазной границы той же гетероструктуры при $\mu_{0} \mathrm{H}=3 T$. С понижением температуры латеральное сопротивление межфазной границы в гетероструктуре LAO/STO уменьшалось, причем наиболее резкое падение $R$ наблюдалось в интервале $100-300 \mathrm{~K}$. Визуализированные температурные зависимости $R$ хорошо экстраполировались соотношением

$$
R=R_{0}+R_{1} T^{2}
$$

где $R_{0}$ и $R_{1}$ независящие от температуры параметры. $R_{0}$ зависело от качества структуры межфазной границы, 


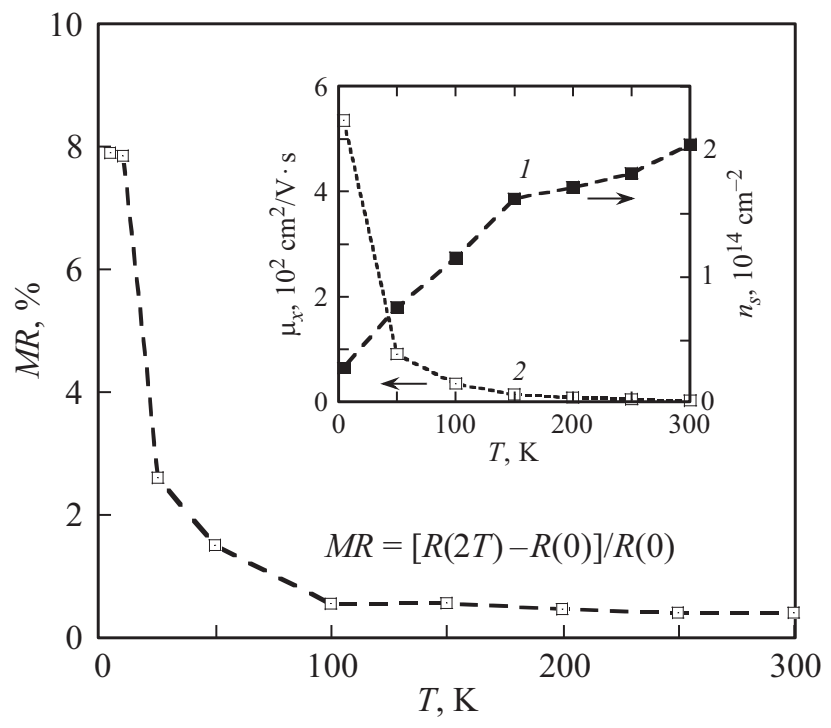

Рис. 3. Температурные зависимости магнетосопротивления межфазной границы в гетероструктуре LAO/STO $(d=6$ u.c., $\mu_{0} \mathrm{H}=3 \mathrm{~T}$ ). Температурные зависимости концентрации электронов $n_{s}$ и их подвижности $\mu_{x}$ показаны на вставке (кривые 1 и 2 соответственно).

а появление квадратично зависящего от температуры второго слагаемого в правой части соотношения (1) может быть обусловлено электрон-электронным взаимодействием [9]. Визуализированные при $\mu_{0} \mathrm{H}=0$ и $\mu_{0} \mathrm{H}=14 T$ зависимости $\left(R-R_{0}\right) v s \cdot T^{2}$ приведены на вставке на рис. 2. Отношение $R_{1} / R_{0}$ имело величину $2.7 \cdot 10^{-4} \mathrm{~K}^{-2}$ и по порядку величины соответствовало аналогичным данным для проводящих манганитов [10].

При комнатной температуре магнитное поле индуцировало незначительное увеличение сопротивления межфазной границы (рис. 2). С понижением температуры отклик сопротивления гетероструктуры на магнитное поле усиливался, а при $T<100 \mathrm{~K}$ наблюдалось резкое увеличение ее положительного магнетосопротивления $(M R)$ (рис. 3). В интервале температуры 4.2-300 К концентрация электронов $n_{s}$ в области межфазной границы находилась в пределах $(0.15-2) \cdot 10^{14} \mathrm{~cm}^{-2}$ (оценка получена с использованием холловских данных). Холловская подвижность $\left(\mu_{x}\right)$ электронов резко возрастала при температурах ниже $100 \mathrm{~K}$ (вставка на рис. 3). Следует отметить, что концентрационные неоднородности в области межфазной границы в гетероструктуре LAO/STO могут существенно влиять на величину $M R$ и на оценки $n_{s}$ и $\mu_{x}[11,12]$.

Титанат стронция является „начинающим“ сегнетоэлектриком, спонтанная поляризация $\left(P_{S}\right)$ в котором не наблюдается вплоть до сверхнизких температур [13]. $P_{S}$ в кристаллах STO может быть, однако, индуцирована электрическим полем и/или механическими напряжениями $[13,14]$. Появление спонтанной поляризации в на- норазмерных, механически напряженных образцах STO наблюдалось вплоть до комнатной температуры [15].

Сжимающие механические напряжения в прослойке подложки, прилегающей к межфазной границе в гетероструктуре LAO/STO, возникают вследствие существенной $(\sim 2.9 \%)$ разницы в параметрах кристаллических решеток LAO и STO. Увеличение толщины слоя LAO, когерентно выращенного на поверхности титаната стронция, индуцирует возрастание уровня механических напряжений в приповерхностном слое STO, что при толщине слоя LAO, превышающей „критическую“, должно приводить к появлению блоков с отличной от нуля спонтанной поляризацией в приповерхностном слое подложки. Присутствие положительно заряженных вакансий кислорода в термообработанной в вакууме подложке STO [3], так же как и наличие электронов в прослойке гетероструктуры со стороны свободной поверхности, способствуют четкой преимущественной ориентации $P_{S}$ в сегнетоэлектрических блоках (перпендикулярно плоскости межфазной границы). Резкое увеличение положительного магнетосопротивления и холловской подвижности электронов наблюдалось при $T \sim T_{S}\left(T_{S}-\right.$ температура спонтанного искажения кристаллической решетки титаната стронция [16]). С понижением температуры объемная доля сегнетоэлектрической фазы в области межфазной границы в гетеросруктуре LAO/STO увеличивалась, что при $T<100 \mathrm{~K}$ сопровождалось увеличением $M R$ и $\mu_{x}$.

\section{4. Заключение}

Проводимость межфазных границ в гетероструктурах LAO/STO зависит от индуцированной механическими напряжениями спонтанной поляризации в приповерхностном слое подложки. Наличие положительно заряженных вакансий кислорода в STO и появившихся в результате катионных замещений $(\mathrm{La} \leftrightarrow \mathrm{Sr})$ электронов в приповерхностном слое гетероструктуры способствуют высокой проводимости межфазной границы в гетероструктурах LAO/STO. Наблюдавшееся резкое увеличение сопротивления указанных границ в магнитном поле обусловлено в значительной степени неоднородностью их латеральной проводимости.

\section{Список литературы}

[1] A. Ohtomo, H.Y. Hwang. Nature (London) 427, 423 (2004).

[2] S. Thiel, G. Hammerl, A. Schmehl, C.W. Schneider, J. Mannhart. Science 313, 1942 (2006).

[3] W. Siemons, G. Koster, H. Yamamoto, W.A. Harrison, G. Lucovsky, T.H. Geballe, D.H.A. Blank, M.R. Beasley. Phys. Rev. Lett. 98, 196802 (2007).

[4] A.S. Kalabukhov, Yu.A. Boikov, I.T. Serenkov, V.I. Sakharov, V.N. Popok, R. Gunnarsson, J. Börjesson, N. Ljustina, E. Olsson, D. Winkler, T. Claeson. Phys. Rev. Lett. 103, 146101 (2009). 
[5] Ю.А. Бойков, И.Т. Серенков, В.И. Сахаров, В.А. Данилов. ФTT 60, 171 (2018).

[6] V.V. Afrosimov, R.N. Ilin, S.F. Karmanenko, A.A. Melkov, V.I. Sakharov, I.T. Serenkov. Thin Solid Films 146, 492 (2005).

[7] F. Voigts, Chr. Argirusis, W. Maus-Friedrichs. Surf. Interface Anal. 44, 301 (2012).

[8] Yu.A. Boikov, I.T. Serenkov, V.I. Sakharov, A.S. Kalabukhov, P.P. Aurino, D. Winkler, T. Claeson. EPL 102, 56003 (2013).

[9] P. Schiffer, A.P. Ramirez, W. Bao, S-W. Cheong. Phys. Rev. Lett. 75, 3336 (1995).

[10] G.J. Snyder, R. Hiskes, S. DiCarolis, M.R. Beasley, T.H. Geballe. Phys. Rev. B 53, 14434 (1996).

[11] S.A. Solin, T. Thio, D.R. Hines, J.J. Heremans. Science 289, 1530 (2000).

[12] A. Kalabukhov, T. Claeson, P.P. Aurino, R. Gunnarsson, D. Winkler, E. Olsson, N. Tuzla, J. Borjesson, Y. Cao, L. Nyborg, Yu.A. Boikov, I.T. Serenkov, V.I. Sakharov, M.P. Volkov. Jpn. J. Appl. Phys. 51, 11PG10 (2012).

[13] K.A. Müller, H. Burkard. Phys. Rev. B 19, 3593 (1979).

[14] J.H. Haeni, P. Irvin, W. Chang, R. Uecker, P. Reiche, Y.L. Li, S. Choudhury, W. Tian, M.E. Hawley, B. Craigo, A.K. Tagantsev, X.Q. Pan, S.K. Streiffer, L.Q. Chen, S.W. Kirchoefer, J. Levy, D.G. Schlom. Nature London 430, 758 (2004).

[15] D. Lee, H. Lu, Y. Gu, S.-Y. Choi, S.-D. Li, S. Ryu, T.R. Paudel, K. Song, E. Mikheev, S. Lee, S. Stemmer, D.A. Tenne, S.H. Oh, E.Y. Tsymbal, X. Wu. Science 349, 6254 (2015).

[16] F.W. Lytle. J. Appl. Phys. 35, 2212 (1964). 